\title{
Long-Term Hyperexcitability in the Hippocampus After Experimental Head Trauma
}

\author{
Vijayalakshmi Santhakumar, BS, ${ }^{1,2}$ Anna D. H. Ratzliff, BS, ${ }^{1}$ Jade Jeng, BS, ${ }^{1}$ Zsolt Toth, MD, PhD, ${ }^{1}$ \\ and Ivan Soltesz, $\mathrm{PhD}^{1}$
}

\begin{abstract}
Head injury is a causative factor in the development of temporal lobe epilepsy. However, whether a single episode of concussive head trauma causes a persistent increase in neuronal excitability in the limbic system has not been unequivocally determined. This study used the rodent fluid percussion injury (FPI) model, in combination with electrophysiological and histochemical techniques, to investigate the early (1 week) and long-term (1 month or longer) changes in the hippocampus after head trauma. Low-frequency, single-shock stimulation of the perforant path revealed an early granule cell hyperexcitability in head-injured animals that returned to control levels by 1 month. However, there was a persistent decrease in threshold to induction of seizure-like electrical activity in response to high-frequency tetanic stimulation in the hippocampus after head injury. Timm staining revealed both early- and long-term mossy fiber sprouting at low to moderate levels in the dentate gyrus of animals that experienced FPI. There was a long-lasting increase in the frequency of spontaneous inhibitory postsynaptic currents in dentate granule cells after FPI, and ionotropic glutamate receptor antagonists selectively decreased the spontaneous inhibitory postsynaptic current frequency in the head-injured animals. These results demonstrate that a single episode of experimental closed head trauma induces long-lasting alterations in the hippocampus. These persistent structural and functional alterations in inhibitory and excitatory circuits are likely to influence the development of hyperexcitable foci in posttraumatic limbic circuits.
\end{abstract}

Ann Neurol 2001;50:708-717

Head injury is an important risk factor in remote symptomatic epilepsy, and accounts for up to $13 \%$ of nonidiopathic epilepsy. ${ }^{1,2}$ After head injury, there is a long-lasting increase in the incidence of epilepsy lasting for several years. ${ }^{1,3,4}$ Although clinical studies have found an association between prior head trauma and temporal lobe epilepsy (TLE), ${ }^{5-7}$ the mechanisms underlying epilepsy following head injury are not understood.

One of the most important unresolved issues regarding posttraumatic epilepsy is whether a single episode of traumatic brain injury leads to a persistent decrease in seizure threshold. The rodent fluid-percussion injury (FPI) model of head trauma has been used to study the anatomical and physiological sequelae of concussive head injury. ${ }^{8}$ After moderate (2-2.2 atmosphere [atm]) FPI in adult rats, there is hilar cell loss, ${ }^{9,10}$ reminiscent of the pattern of histopathological changes accompanying end-folium sclerosis in TLE. ${ }^{9-12}$ However, the degree of hyperexcitability in limbic circuits after FPI has been studied only at the early time points (up to 1 week). The dentate granule cells at this early time point have been found to show hyperexcitable responses to low-frequency (single shock) stimulation of the perforant path in animals that experienced moderate FPI. ${ }^{9,10,13}$ In addition, 1 week after FPI, hippocampal-entorhinal cortex $(\mathrm{HEnC})$ slices were reported to show a decreased threshold to self-sustaining, seizure-like electrical field activity in response to high-frequency, tetanic stimulation. ${ }^{14}$ These studies demonstrated early dentate hyperexcitability after experimental head trauma, both in response to low- and high-frequency stimulation. However, whether the post-FPI hyperexcitability in the hippocampus is persistent or transient on a time scale of weeks and months is not known. Long-term behavioral changes ${ }^{15}$ and progressive cell $\operatorname{loss}^{16,17}$ have been reported after severe (2.5-2.9atm) FPI with cortical cavitation. Following moderate FPI, dentate hilar cell loss has been observed up to 5 months, ${ }^{10,13}$ and the maintenance of synaptic plasticity is impaired for as long as 2 months. ${ }^{18}$ However, the long-term posttraumatic changes in hippocampal excitability have not been investigated.
From the ${ }^{1}$ Department of Anatomy and Neurobiology, and ${ }^{2}$ ReeveIrvine Research Center, University of California, Irvine, CA.

Received May 7, 2001, and in revised form Jul 18. Accepted for publication Jul 18, 2001.
Address correspondence to Ms Santhakumar, Department of Anatomy and Neurobiology, University of California, Irivne, CA 926971280. E-mail: vsanthak@uci.edu 
In addition, apart from the characteristic loss of hilar cells, possible structural alterations that may contribute to posttraumatic epilepsy are also not well understood. It is not known whether granule cell axons (the mossy fibers) undergo a posttraumatic long-term structural reorganization (sprouting) in a manner similar to what takes place in the dentate gyrus of epileptic patients, ${ }^{19-22}$ or in the dentate gyrus of experimental animals in various models of temporal lobe epilepsy. ${ }^{23-26}$ Previous reports indicate that the dentate gyrus of epileptic patients with a history of head trauma may show supragranular sprouting of mossy fibers ${ }^{27,28}$; however, there is no conclusive, direct experimental evidence for mossy fiber sprouting after traumatic brain injury. ${ }^{29,30}$

This study was performed to determine the existence of long-term limbic hyperexcitability following a single episode of concussive head injury. Specifically, we focused on three major areas: (1) Does FPI in the rat result in persistent changes in the hippocampal response to low- and high-frequency stimulation; (2) Is there evidence for mossy fiber reorganization in the fluid percussion injured animals; and (3) Are there long-term alterations in the interactions of inhibitory and excitatory neuronal networks after head injury?

\section{Materials and Methods}

\section{Lateral Fluid Percussion Injury}

The lateral fluid percussion head trauma was carried out as described previously. ${ }^{8-10,13}$ All procedures described were approved by the Institutional Animal Care and Use Committee, University of California, Irvine, CA. The fluid percussion device (Department of Biomedical Engineering, Virginia Commonwealth University, Richmond, VA; see Toth et $\mathrm{al}^{8-10,13}$ for detailed description) was used to deliver a brief (20msec), 2.0 to $2.2 \mathrm{~atm}$ impact on the intact dura. This resulted in a moderate level of injury that has been shown to cause a highly reproducible pattern of more than $50 \%$ hilar cell loss. ${ }^{9}, 10$ Injured and age-matched sham-operated control animals were euthanized at various time points for slice physiology or Timm staining.

\section{Slice Preparation}

The animals were anesthetized with sodium pentobarbital $(65 \mathrm{mg} / \mathrm{kg}$ ip) and decapitated. Horizontal brain slices $(400 \mu \mathrm{m})$ were cut using a vibratome tissue sectioner (Lancer series 1000; TPI, St Louis, MO) as previously described ${ }^{31}$ for the field and whole-cell recordings. The slices were sagittally bisected and the slices ipsilateral to the side of injury were submerged in $32^{\circ} \mathrm{C}$ artificial cerebral spinal fluid (ACSF) composed of $126 \mathrm{mM} \mathrm{NaCl}, 2.5 \mathrm{mM} \mathrm{KCl}, 2 \mathrm{mM} \mathrm{MgCl}_{2}, 26 \mathrm{mM}$ $\mathrm{NaHCO}_{3}, 2 \mathrm{mM} \mathrm{CaCl}_{2}, 1.25 \mathrm{mM} \mathrm{NaH}_{2} \mathrm{PO}_{4}$, and $10 \mathrm{mM}$ glucose for 1 to 4 hours.

HEnC slices in which the trisynaptic circuit is preserved were prepared as previously described. ${ }^{14,32-34}$ Briefly, the brains were incubated for 2 minutes in $4^{\circ} \mathrm{C}$ oxygenated $\left(95 \% \mathrm{O}_{2}, 5 \% \mathrm{CO}_{2}\right)$ sucrose ACSF composed of $200 \mathrm{mM}$ sucrose, $3 \mathrm{mM} \mathrm{KCl}, 0.9 \mathrm{mM} \mathrm{MgCl}_{2}, 26 \mathrm{mM} \mathrm{NaHCO}, 2 \mathrm{mM}$
$\mathrm{CaCl}_{2}, 1.25 \mathrm{mM} \mathrm{NaH}_{2} \mathrm{PO}_{4}$, and $10 \mathrm{mM}$ glucose. The dorsal surface of the brain was glued onto a 12-degree agar ramp with the rostral end pointed up, and $450 \mu \mathrm{m}$ brain slices were sectioned with a vibratome tissue slicer (Leica VT1000S; Leica, Nussloch, Germany). The slices ipsilateral to the injury were preincubated in $32^{\circ} \mathrm{C}$ oxygenated low $\mathrm{Mg}^{2+}$-ACSF containing $130 \mathrm{mM} \mathrm{NaCl}, 3 \mathrm{mM} \mathrm{KCl}$,

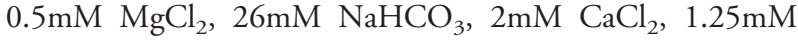
$\mathrm{NaH}_{2} \mathrm{PO}_{4}$, and $10 \mathrm{mM}$ glucose to promote polysynaptic interactions. $^{33,34}$

\section{In Vitro Electrophysiology}

Slices were transferred to the recording chamber ${ }^{35,36}$ and perfused with oxygenated ACSF or low $\mathrm{Mg}^{2+}$-ACSF (for the $\mathrm{HEnC}$ slices) at $36^{\circ} \mathrm{C}$. In some experiments the perfusion was switched to ACSF containing $20 \mu \mathrm{M}$ bicuculline methiodide (BMI) or $20 \mu \mathrm{M}$ 2-amino-5-phosphovaleric acid (APV) and $5 \mu \mathrm{M}$ 6-cyano-7-nitroquinoxaline-2,3-dione (CNQX). (All salts were obtained from Fluka, Buchs, Switzerland; APV and CNQX obtained from Tocris, Avonmouth, UK; and BMI from RBI, Natick, MA).

"Blind" whole-cell recordings were obtained as previously described, ${ }^{31}$ using patch pipettes filled with internal solution that consisted of $140 \mathrm{mM}$ Cs-gluconate, $2 \mathrm{mM} \mathrm{MgCl}_{2}$, and $10 \mathrm{mM} \mathrm{N}$-2-hydroxyethylpiperazine- $\mathrm{N}^{\prime}$-2-ethane-sulfonic acid. Granule cell population responses were evoked by constant-current stimuli $(0.5-8 \mathrm{~mA}, 50 \mu \mathrm{s})$ applied at $0.1 \mathrm{~Hz}$ through a bipolar tungsten stimulating electrode placed in the perforant path at the junction of the dorsal blade and the crest. The field responses in the granule cell layer were measured at five predetermined points, including the tips of the dorsal and ventral blades, the middle of the dorsal and ventral blades, and the middle of the crest, and the largest response was studied further. The input-output relationship in both control and injured animals was obtained by comparing the amplitudes of the population spikes evoked at each stimulation intensity. ${ }^{10,13}$ Field recordings in the HEnC slices were obtained from the CA1 pyramidal cell layer. The tetanic stimulation consisted of a 2 -second, $60 \mathrm{~Hz}$ train of stimuli applied to the Schaeffer collaterals with a pulse width of $0.1 \mathrm{msec}$ through a stimulating electrode in the CA1 stratum radiatum. ${ }^{14,33,34}$ Stimulus was delivered at four times the minimal intensity required to evoke a $0.5 \mathrm{mV}$ population spike $(4-6 \mathrm{~mA})$. A maximum of 10 stimuli were given at 10-minute intervals (to avoid interference by postictal refractory periods). Once sustained epileptiform activity developed, recording was terminated after 30 minutes (time point selected to correspond to the clinical definition of status epilepticus, see Coulter et $\mathrm{al}^{14}$ ).

\section{Timm Staining}

One week ( 2 controls and 3 FPI) and 3 months ( 3 controls and 7 FPI) after injury, control and injured animals were deeply anesthetized and perfused transcardially with an aqueous solution of $0.4 \%(\mathrm{wt} / \mathrm{vol})$ sodium sulfide followed by $500 \mathrm{ml} 1.25 \%(\mathrm{wt} / \mathrm{vol})$ gluteraldehyde and $500 \mathrm{ml}$ of the aqueous solution of $0.4 \%(\mathrm{wt} / \mathrm{vol})$ sodium sulfide. The hippocampus was sectioned $(30 \mu \mathrm{m})$, and every 20 th section was mounted and developed in the dark for 30 to 60 minutes in Timm solution $(40 \mathrm{ml}$ distilled water, $2.55 \mathrm{~g}$ citric acid, $2.35 \mathrm{~g}$ 
sodium citrate, $1.7 \mathrm{~g}$ hydroquinone, $60 \mathrm{ml}(50 \% \mathrm{wt} / \mathrm{vol}) \mathrm{gum}$ arabic, and $0.1 \mathrm{~g}$ silver nitrate) at $56^{\circ} \mathrm{C} .{ }^{34,37}$ Sections were washed in distilled water, placed in $1 \%$ (wt/vol) sodium thiosulphate, washed again, and counterstained with $1 \%$ creysl violet acetate. The entire inner molecular layer of the dentate gyrus (ie, from the tip of the dorsal blade to the tip of the ventral blade of the dentate gyrus) from individual sections was examined by a blinded observer. Timm scores for sprouting were assigned to the sections based on the 0 to 5 scale of Cavazos and colleagues. ${ }^{25}$ Briefly, $0=$ no granules; $1=$ sparse granules in the supragranular layer; $2=$ more numerous granules in the supragranular layer in a continuous distribution; 3 = prominent granules in the supragranular layer in a continuous pattern with patches of confluent granules; $4=$ prominent granules in the supragranular region that form confluent dense laminar bands; and $5=$ confluent dense laminar band of granules in the supragranular region extending into the inner molecular layer.

\section{Analysis}

Recordings were filtered at $3 \mathrm{kHz}$, digitization at $20 \mathrm{kHz}$ using Strathclyde Electrophysiology Software (courtesy of Dr J. Dempster, University of Strathclyde, Glasgow, UK) and Synapse software (courtesy of Dr Y. De Koninck, McGill University, Montreal, Canada). The spontaneous inhibitory postsynaptic current (sIPSC) interevent interval (IEI) was obtained by sampling 100 sIPSCs from each cell. The efficiency of inhibition was measured on the amplitude of the evoked population spike. It was calculated as the ratio of the amplitude difference between bicuculline and ACSF recordings to the amplitude of bicuculline recordings.

$$
\text { Efficiency of inhibition (\%) }=\frac{\begin{array}{c}
\text { Amplitude in bicuculline } \\
\text { Amplitude in bicuculline }
\end{array}}{\text { Amplitude in ACSF }} \text {. }
$$

Statistical analyses were performed with SigmaPlot or SPSS for Windows. The significance of differences in field recordings from the dentate gyrus of control and injured animals was evaluated using Student's $t$ test. The nonparametric Mann-Whitney $U$ test was used to assess the significance of difference in the $\mathrm{HEnC}$ slice experiments and Timm scoring, as the data from these experiments are not normally distributed. KolmogorovSmirnov test was used to assess the difference in the distribution of sIPSC IEI in control and injured animals. The level of significance was set at $p<0.05$. Data are presented as mean \pm standard error.

\section{Results \\ Long-Term Recovery of Early Hyperexcitability to Low-Frequency Stimulation}

Previous studies conducted 1 week after FPI in rats have shown an increase in the evoked field potential amplitude recorded in the granule cell layer in response to perforant path stimulation both in vivo ${ }^{9}$ and in vitro $^{10,14}$ in control ACSF (ie, without the presence of various neuotransmitter receptor blockers in the extra- cellular medium). One week after FPI, the population spike amplitude, recorded in ACSF in response to single-shock stimulation of the perforant path (stimulus intensities: $2-8 \mathrm{~mA}$ ), was significantly $\operatorname{larger}^{10}$ in the head-injured animals compared to the agematched, sham-operated controls (eg, at $4 \mathrm{mV}$ stimulation intensity, the population spike amplitudes were: control $=0.16 \pm 0.11 \mathrm{mV}$ from 3 animals, $\mathrm{n}=9$ slices; FPI $=1.08 \pm 0.22 \mathrm{mV}$ from 4 animals, $\mathrm{n}=12$; for examples of complete input-output curves at multiple stimulation intensities, see Toth et $\mathrm{al}^{10}$ and Santhakumar et $\left.\mathrm{al}^{13}\right)$. However, the evoked population spike amplitude 1 month and 3 months after FPI was not different from controls at any stimulation intensity $(0.5-8 \mathrm{~mA}$; Fig 1A: control $=0.17 \pm 0.12 \mathrm{mV}$ at 1 month, $\mathrm{n}=9 ; 0.47 \pm 0.03 \mathrm{mV}$ at 3 months, $\mathrm{n}=13$; 3 animals each; FPI $=0.34 \pm 0.17 \mathrm{mV}$ at 1 month, $\mathrm{n}=10 ; 0.63 \pm 0.23 \mathrm{mV}$ at 3 months, $\mathrm{n}=12 ; 3$ animals each; $4 \mathrm{~mA}$ stimulation intensity). These data indicate a recovery of the early dentate posttraumatic hyperexcitability in response to low-frequency stimulation.

Perturbed inhibition in the dentate gyrus ${ }^{38,39}$ has been suggested to play a role in the early posttraumatic hyperexcitability. ${ }^{10,36}$ Could the recovery of the granule cell field responses to single-shock perforant path stimulation be explained by recovery of inhibition? To answer this question, we determined whether there is a recovery of the early hyperexcitable response during the early (1-week) to long-term (3-month) post-FPI period even when fast inhibition is blocked. Bicuculline $(20 \mu \mathrm{M})$ was included in the perfusing medium to block the $\gamma$-animobutyric acid $(\mathrm{GABA})_{\mathrm{A}}$-mediated feedforward inhibition. ${ }^{13,36}$ As expected, addition of bicuculline increased the amplitude of the population spike both in the post-FPI and control slices (see Fig 1A and B). One week after FPI, as described previously, ${ }^{13}$ the population spike amplitude in bicuculline was larger in the head-injured animals compared to controls (at stimulation intensities from $1-8 \mathrm{~mA}$ ) (see Fig 1B; control $=2.33 \pm 0.66 \mathrm{mV}, \mathrm{n}=9$; FPI $=5.75 \pm 0.77 \mathrm{mV}$, $\mathrm{n}=12$; stimulus intensity $=4 \mathrm{~mA}$ ). However, there was no difference in the field potential amplitude between control and head-injured animals at later time points even in the presence of bicuculline at any stimulation intensity $(0.5-8 \mathrm{~mA}$; see Fig $1 \mathrm{~B}$ and $\mathrm{C}$; 1 month after FPI: control $=1.43 \pm 0.42 \mathrm{mV}, \mathrm{n}=9$; FPI $=2.03 \pm$ $0.62 \mathrm{mV}, \mathrm{n}=10 ; 3$ months: control $=1.45 \pm$ $0.24 \mathrm{mV}, \mathrm{n}=13$; FPI $=1.23 \pm 0.26 \mathrm{mV}, \mathrm{n}=12$ ). These data indicate that the early posttraumatic hyperexcitabile response of the dentate glutametergic network to low-frequency stimulation recovers by 1 month, and that the recovery cannot be the result of a possible recovery of the perturbed fast synaptic inhibitory control of granule cells.

These field recording data, obtained both in ACSF 
A

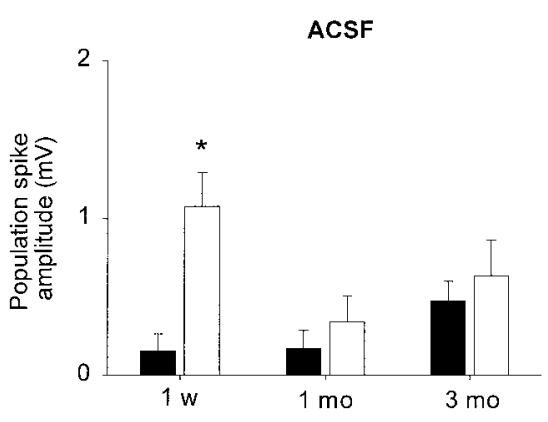

C

\section{B}

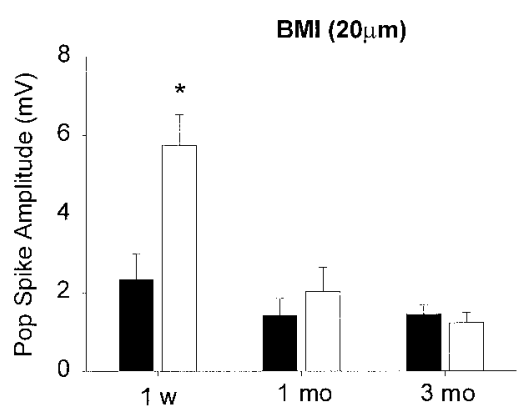

3-Month FPI

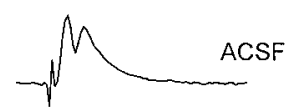

D

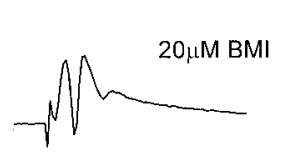

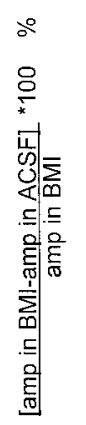

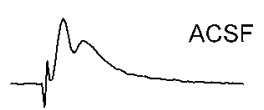

$$
\text { D }
$$

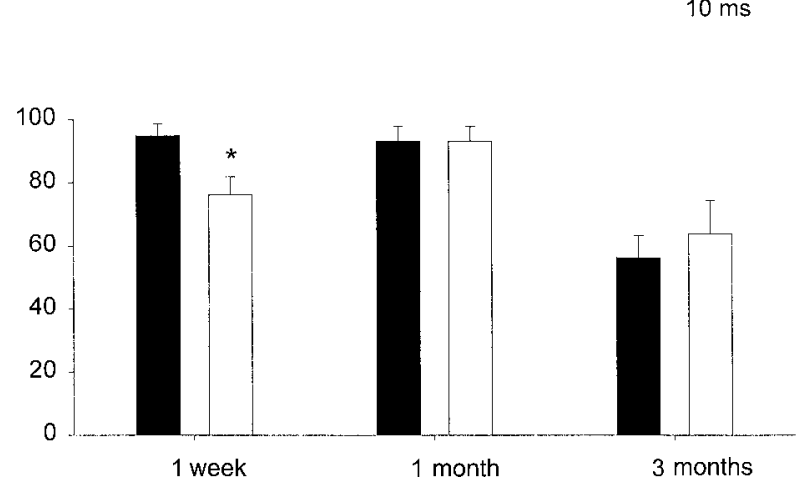

Fig 1. Long-term recovery of the hyperexcitable granule cell responses to lowfrequency stimuli. Dark bars indicate controls, light bars indicate fluid percussion injury (FPI). (A and B) Summary data of the amplitude of the perforant path-evoked granule cell population spike show that the enhanced excitability observed at 1 week is not present at 1 month and 3 months after FPI, both in control artificial cerebral spinal fluid (ACSF; A); and in $20 \mu M$ bicuculline (BMI; B). Stimulation intensity $=4 m V$. (C) Averages of representative granule cell field responses from FPI and sham operated control animals 3 months after injury illustrate the absence of enhanced excitability in ACSF and in $20 \mu M$ BMI. The initial deflection of the evoked response is the truncated stimulus artifact. Stimulation intensity $=6 \mathrm{~mA}$. (D) Efficiency of inbibition in the dentate gyrus is significantly decreased 1 week after injury, but it is not statistically different from control animals at later time points. Calculation of the efficiency of inhibition: the population spike amplitude suppressed by feedforward inhibition was obtained from the difference between the amplitude in BMI $(20 \mu M)$ and in ACSF. This difference was normalized to the population

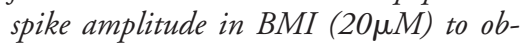
tain the efficiency of inbibition. Asterisks indicate significance $(\mathrm{p}<0.05$, Student's $\mathrm{t}$ test). and bicuculline, also made it possible to calculate the amount of granule cell firing that is blocked by $\mathrm{GABA}_{\mathrm{A}}$ receptor-dependent fast inhibition, providing a measure of the efficiency of inhibition in control and headinjured animals at the various time points. The difference between the population spike amplitude in bicuculline and ACSF was normalized to the amplitude of the field potential in bicuculline (see Materials and Methods). The efficiency of inhibition was significantly depressed in the head-injured animals at 1 week (control $=94.9 \pm 3.7 \%, \mathrm{n}=9$; FPI $=76.1 \pm 5.7 \%$, $\mathrm{n}=12$ ), but recovered to control levels by 1 month (control $=93.1 \pm 4.6 \%, \mathrm{n}=9$; FPI $=93.1 \pm 4.5 \%$, $\mathrm{n}=10$ ) and 3 months (control $=56.3 \pm 6.8 \% ; \mathrm{n}=$ 13 ; FPI $=63.7 \pm 10.4 \% ; \mathrm{n}=12$ ) (see Fig $1 \mathrm{D})$. These data demonstrate long-term recovery of the early posttraumatic decrease in the efficiency of dentate inhibition.

\begin{abstract}
Persistent Decrease in Threshold to Evoke SelfSustaining Seizure-Like Population Discharges After Fluid Percussion Injury

Taken together, the data described above indicated a recovery of the field responses in the dentate gyrus by 1 month in response to single-shock stimulation. Is it possible that this recovery is incomplete, and that when the neuronal network is challenged with stronger stimuli, the system reveals a persistently decreased seizure threshold? To answer this question, tetanic stimulation was applied to excitatory pathways as a form of a more robust stimulation paradigm to test the stability of the system. These experiments were performed at a time point when there was a full recovery of the early hyperexcitable field responses to single-shock stimulation, ie, at 3 months after FPI. The experiments with tetanic stimulation were carried out in a preparation that preserves the trisynaptic hippocampal-entorhinal pathway,
\end{abstract}




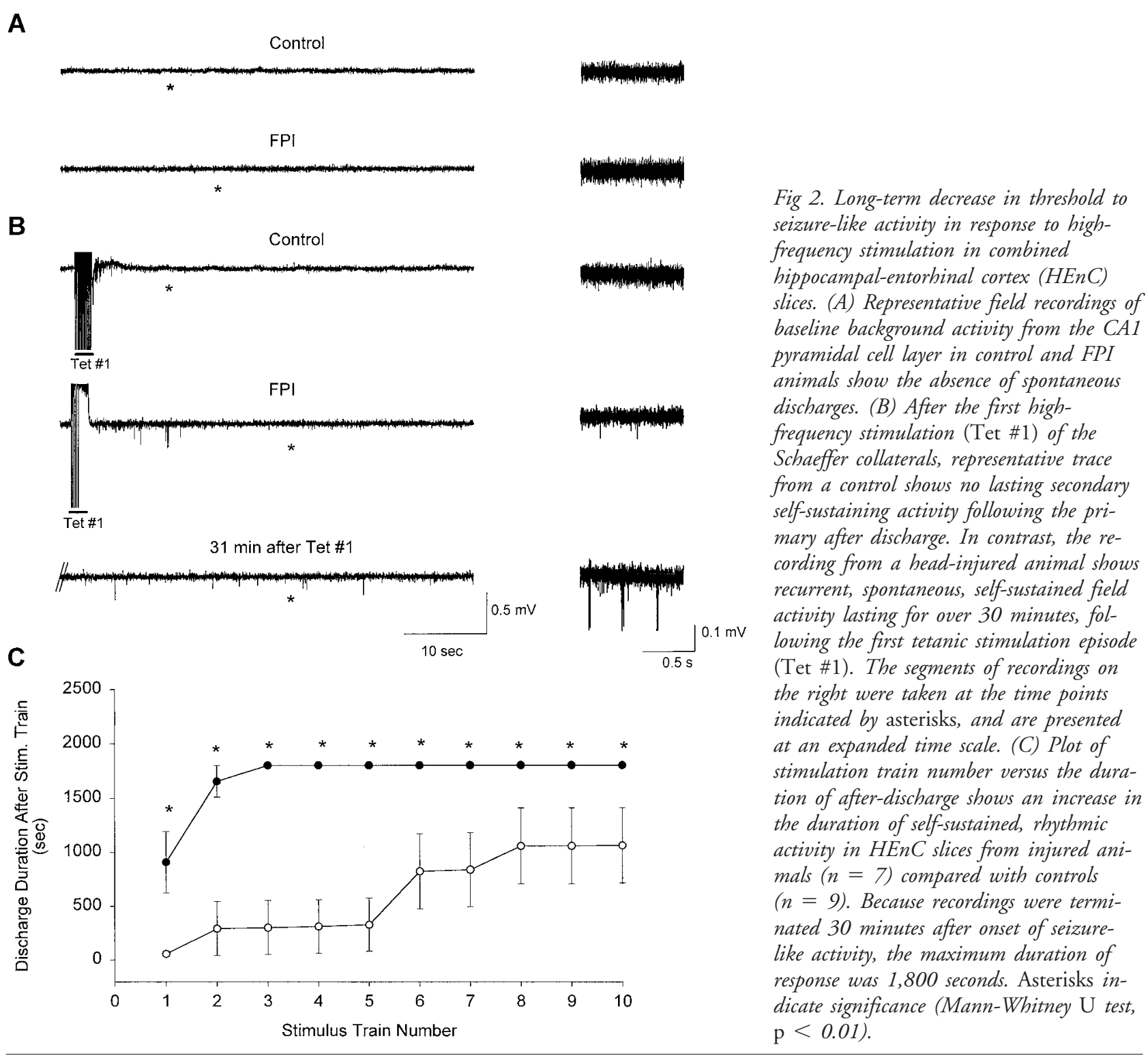

namely, in the combined HEnC slice ${ }^{40}$ that allows the development of self-sustaining seizure-like events. As described before, ${ }^{33,34,40}$ field recordings in this preparation are best studied in the CA1 region because of the high signal (population spike amplitude)-to-noise ratio and stability of recorded events. The HEnC slices from control and head-injured rats did not display spontaneous field discharges in the CA1 pyramidal cell layer (Fig 2A). Tetanic stimulation of the Schaeffer collaterals $(60 \mathrm{~Hz}$ train with a pulse width of $100 \mu \mathrm{s}$, lasting 2 seconds) in slices from control animals induced a primary after-discharge that lasted less than $120 \mathrm{sec}-$ onds (see Fig 2B). Among slices from the head-injured animals, $44.4 \%$ showed self-sustaining, recurrent epileptiform activity following the first tetanic stimulation, and all slices $(n=9)$ showed prolonged $(>30$ minutes) seizure-like activity after the third tetanic stimulation (see Fig 2B and C). In contrast, $85.7 \%$ of slices from control animals showed no evidence of recurrent seizure-like activity even after the third train of tetanic stimulation (see Fig 2C). Once the seizure-like activity developed, it was also observed in the CA3 region and the dentate granule cell layer (not shown). Therefore, these data show that although there is no spontaneous seizure-like activity in the posttraumatic hippocampus, there is a persistent decrease in the threshold for generation of self-sustaining epileptiform activity when the system is challenged with a strong stimulus long after a single head injury episode.

\section{Posttraumatic Mossy Fiber Reorganization}

Timm staining for the zinc-containing mossy fiber terminals ${ }^{25,37}$ was performed on hippocampal sections 1 week and 3 months after head injury to determine the 
presence of aberrant mossy fiber sprouting in the inner molecular layer of the dentate gyrus. Timm scores ${ }^{25}$ were assigned by a blinded observer evaluating the entire supragranular region of the dentate gyrus (ie, the entire inner molecular layer from the tip of the dorsal blade to the tip of the ventral blade of the dentate gyrus) to estimate the density of sprouting (see Materials and Methods). None of the 32 sections from controls 3 months after sham head injury had abnormal Timm staining (none had a Timm score $\geq 1$; Fig $3 \mathrm{~A}, \mathrm{C}$, and E). In contrast, 3 months after trauma, $53 \%$ of the sections from the head-injured animals (37 of 70 sections) had numerous Timm granules in the supragranular region with occasional confluent patches (Timm score $\geq 2$; see Fig 3B, D, and F). There was no evidence of confluent dense bands of Timm granules in the supragranular layer (Timm score $\geq 4$ ) in any of the sections from the head-injured animals, indicating that the degree of the mossy fiber sprouting was relatively low. Interestingly, $25 \%$ of the sections from headinjured animals showed numerous Timm granules in the supragranular region (Timm score $>2 ; 18$ of 73 sections) even 1 week after FPI, indicating the rapid onset of supragranular mossy fiber sprouting (see Fig $3 \mathrm{G})$. The increase in sprouting observed in the sections from the head-injured compared to control animals was significant both at 1 week (Timm scores: control $=0.45 \pm 0.08$; FPI $=1.27 \pm 0.08)$ and 3 months (control $=0.41 \pm 0.09$; FPI $=1.57 \pm 0.12$ ) (see Fig 3G). Additionally, the post-injury increase in sprouting was significantly higher at 3 months compared to 1 week after injury.

\section{Prolonged Increase in the Frequency of sIPSCs in} Granule Cells After Fluid Percussion Injury

The posttraumatic presence of the moderate but significant mossy fiber sprouting indicates an increase in the axonal output from the excitatory principal cells of the dentate gyrus, most likely both to other granule cells and to interneurons. Is there a similar increase in the output from posttraumatic dentate interneurons? In lieu of a convenient histochemical marker such as the Timm stain, an alternative strategy was applied to answer this question. It has been shown that FPI at 2.0 to $2.2 \mathrm{~atm}$ impact strength in our laboratory results in the loss of about $50 \%$ of the parvalbumin- and cholecytokinin-positive basket and axo-axonic cells, ${ }^{10}$ as well as other interneurons. ${ }^{13}$ The loss of interneurons was found to be accompanied by a permanent decrease in the frequency of the spontaneous, action potential-independent miniature IPSCs, ${ }^{10}$ indicating a posttraumatic decrease in GABAergic release sites or probability of GABA release. To determine whether the net synaptic output of the surviving inhibitory interneuronal network is altered in a persistent manner after head trauma, we examined the posttraumatic
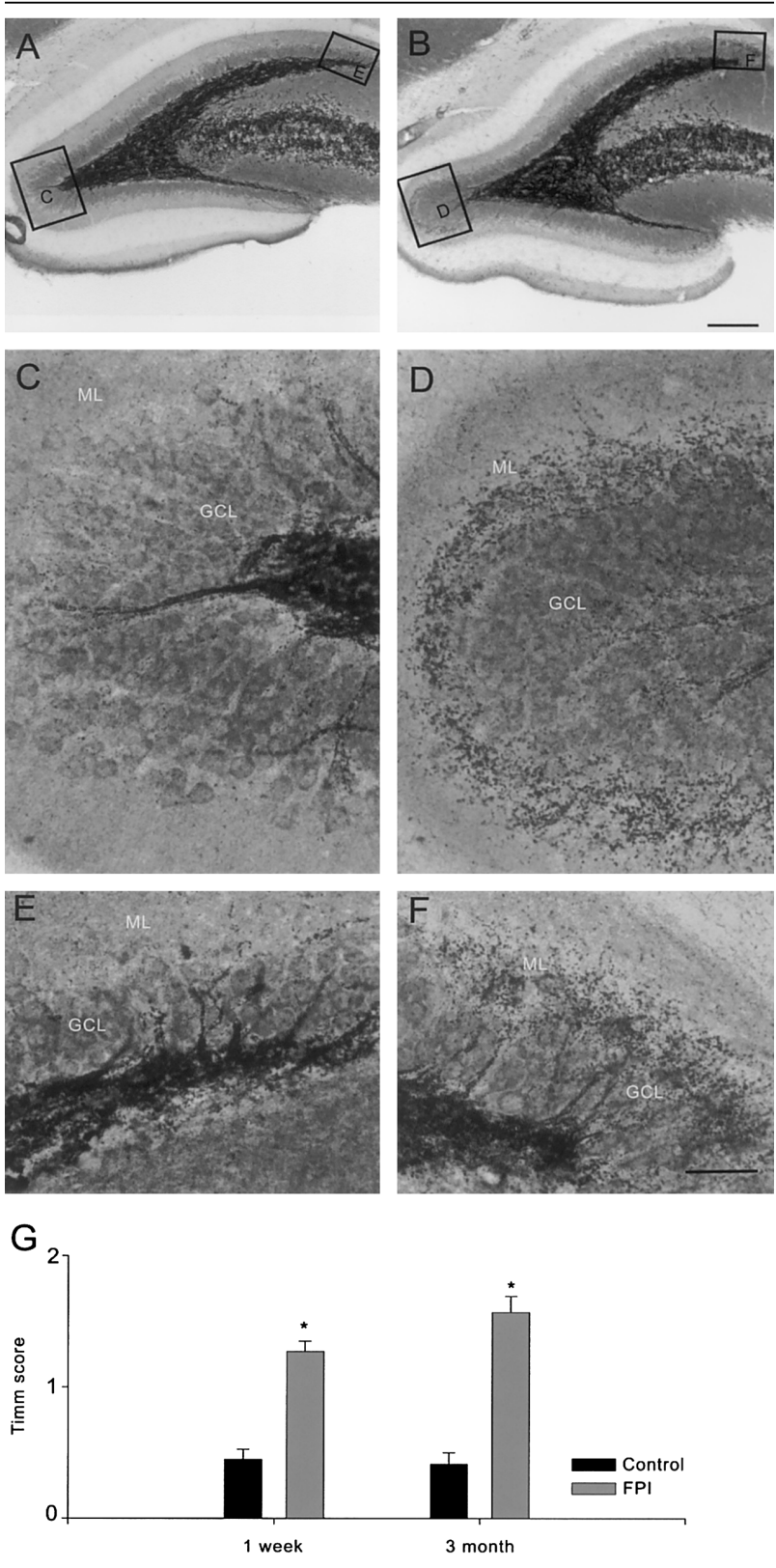

Fig 3. Reorganization of the dentate granule cell axons following trauma. (A-F) Timm staining shows mossy fiber sprouting in the dentate gyrus of FPI animals 3 months after injury. A and $B$ are low-magnification images of the dentate gyrus; outlined areas are shown at higher magnification in $C$ through $F$. Note the absence of black granules in the supragranular layer of the control $(A, C$, and $E$ ) compared with the FPI ( $B$, $D$, and $F$ ). $C$ and $D$ are from the crest, and $E$ and $F$ are from the suprapyramidal blade of the granule cell layer. $(G)$ Summary data of Timm scores show a significant increase in sprouting in the head-injured animals compared to agematched, sham-operated controls. Asterisks indicate significance (Mann-Whitney U test, $\mathrm{p}<0.001)$. ML = molecular layer; $\mathrm{GCL}=$ granule cell layer. Bar $=200 \mu m(A$ and $B)$ and $50 \mu \mathrm{m}(C-F)$. 
changes in the frequency of the spontaneous, action potential-dependent sIPSCs from granule cells, 1 week and 5 to 6 months after head injury. The sIPSCs were recorded at $0 \mathrm{mV}$, with Cs-gluconate-filled patch pipettes, in ACSF. The sIPSC IEI was significantly smaller (ie, the frequency was higher) in the headinjured animals compared with the age-matched controls at both the early (control $=37.72 \pm 1.28 \mathrm{msec}$, $\mathrm{n}=9$; FPI $=18.20 \pm 0.05 \mathrm{msec}, \mathrm{n}=8$ ) and late (control $=109.22 \pm 4.86 \mathrm{msec}, \mathrm{n}=7$; FPI $=$ $66.52 \pm 2.47 \mathrm{msec}, \mathrm{n}=12$ ) post-FPI time points (Fig $4 \mathrm{~A})$. The amplitude of the sIPSCs was significantly larger in the head-injured animals (control $=35.88 \pm$

Fig 4. Increase in granule cell spontaneous inhibitory postsynaptic current (sIPSC) frequency after FPI. (A) Summary data of SIPSC interevent interval (IEI) in head-injured animals as a percent of SIPSC IEI in the age-matched controls. Note the decrease in IEI (increased sIPSC frequency) after injury at both time points. (B) Summary data show that the glutamate receptor antagonists $A P V(20 \mu M)$ and $C N Q X(5 \mu M)$ increased the lower IEI of SIPSCS (decreased the elevated SIPSC frequency) in granule cells from animals that experienced head injury, but not in controls. Asterisks indicate significance (Kolmogorov-Smirnov test, $\mathrm{p}<0.05$ ).
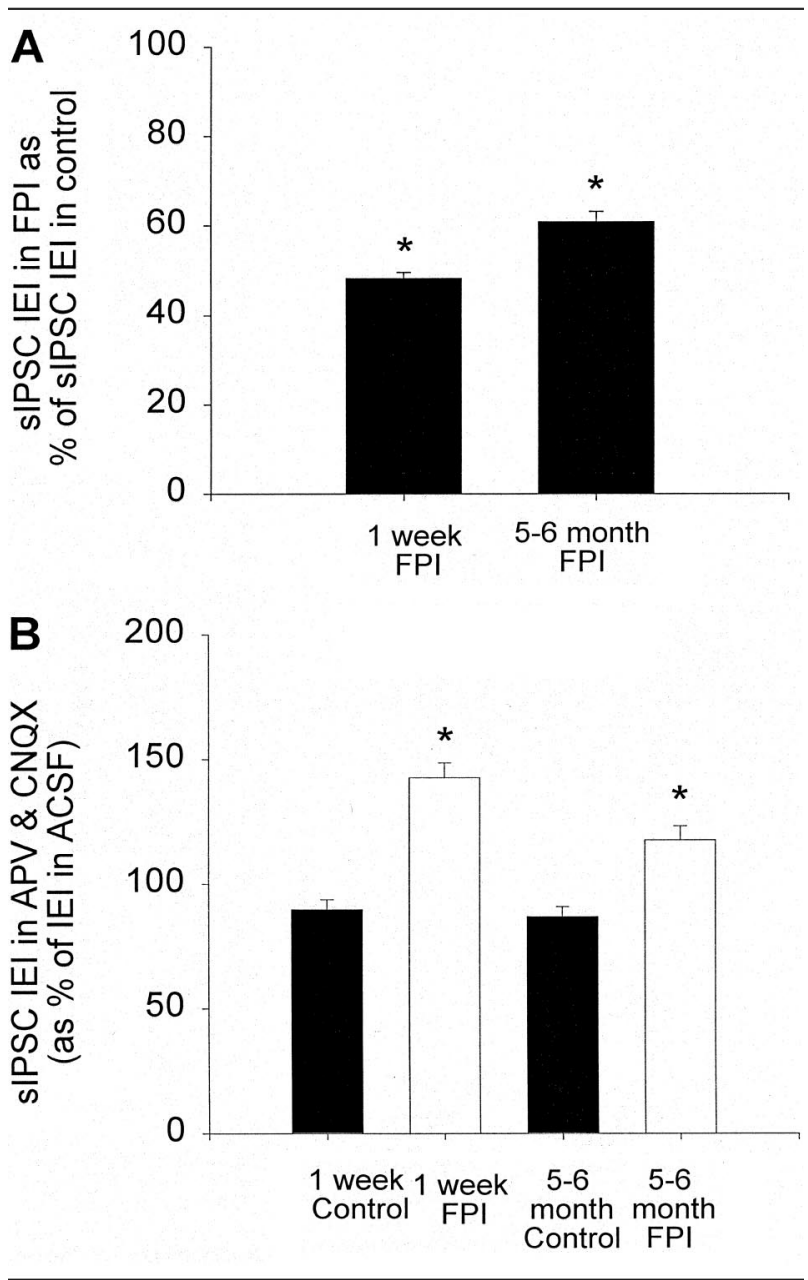

$1.15 \mathrm{pA} ; \mathrm{FPI}=40.59 \pm 1.29 \mathrm{pA}, \mathrm{n}=8$ cells each) 1 week after FPI. However, the rise time constants (control $=1.06 \pm 0.12 \mathrm{~ms} ;$ FPI $=1.11 \pm 0.20 \mathrm{~ms}, \mathrm{n}=8$ each) and decay time constants (control $=5.46 \pm$ $0.37 \mathrm{~ms}$; FPI $=4.65 \pm 0.36 \mathrm{~ms}, \mathrm{n}=8$ each) of the sIPSCs from head-injured animals were not different from controls. Is the posttraumatic increase in the frequency of sIPSCs in granule cells influenced by the excitatory drive to interneurons? ${ }^{41-45}$ To answer this question, the frequency of sIPSCs from granule cells in the control medium (ACSF) were compared to the frequency of sIPSCs in a medium containing ionotropic glutamate receptor antagonists $(20 \mu \mathrm{M}$ APV and $5 \mu \mathrm{M}$ CNQX). As shown before, ${ }^{41-45}$ the sIPSC frequency is not influenced significantly in control granule cells by the presence of the ionotropic receptor blockers in the perfusate (sIPSC IEI in APV and CNQX, with respect to IEI in ACSF: $89.6 \pm 4.0 \%$ at 1 week, $\mathrm{n}=6$; and $86.6 \pm 4.1 \%$ at $5-6$ months, $n=6$, after sham injury). In contrast, APV and CNQX significantly decreased the enhanced sIPSC frequency observed after head trauma (see Fig 4B; IEI in APV and CNQX, with respect to IEI in ACSF at 1 week: $142.6 \pm 5.9 \%, \mathrm{n}=$ 6; 5-6 months: $117 \pm 5.5 \%, \mathrm{n}=7)$. These findings indicate that the glutamatergic excitatory drive to interneurons contributes to the early and long-term posttraumatic increase in the net output from the dentate inhibitory network.

\section{Discussion}

This study demonstrates the permanent decrease in threshold to seizure-like activity, and long-term structural and functional hippocampal reorganization affecting both excitatory and inhibitory networks, after a single episode of concussive head injury. Specifically, the data show that (1) the early hyperexcitability to low-frequency stimulation recovers within 1 month; (2) there is a long-term decrease in the stability of the neuronal network, as determined by the decreased threshold for generation of seizure-like activity in response to high-frequency stimulation; (3) without tetanic stimulation, there are no spontaneous epileptiform discharges in the hippocampal circuit; (4) mossy fiber sprouting appears within 1 week after injury and increases in density by 3 months; (5) the early increase in the frequency of granule cell sIPSCs persists at least 5 months after FPI; and (6) ionotropic glutamate receptor antagonists decrease the the posttraumatic potentiation of the sIPSC in dentate granule cells.

\section{Alterations in Limbic Excitability After Head Injury}

Each year an estimated 1.5 million people sustain traumatic brain injury in the United States, and brain trauma is the leading cause of death and disability among young adults. ${ }^{46}$ The annual economic burden of traumatic brain injury is projected to exceed $\$ 40$ 
billion. ${ }^{46,47}$ Therefore, head injuries present an enormous medical and social problem. A major consequence of traumatic brain injury is epilepsy. The risk of epilepsy increases with the severity of the head injury. Immediate posttraumatic seizures are frequently followed by a latent period, ${ }^{6}$ during which epileptogenesis can take place. However, the nature of the processes underlying the development of later unprovoked seizures is not understood. Clinical trials aimed at prevention of late posttraumatic epilepsy using antiepileptic drugs have been largely unsuccessful. ${ }^{48,49}$ A recent experimental study, however, has shown that activitydependent processes shortly after trauma are likely to play a major role in the development of posttraumatic hyperexcitability. ${ }^{50}$

Our data show that the early dentate hyperexcitability recovers within a month after FPI. However, when challenged with high-frequency stimulation, the injured hippocampal network exhibits a lower threshold to generation of seizure-like activity even 3 months after injury. These findings indicate that, although there are no persistent spontaneous seizure-like events in the trisynaptic circuit after injury, there are underlying long-term changes that predispose the limbic system to seizures when challenged with strong stimuli. In other words, following the initial impact, the hippocampal network becomes persistently hyperexcitable, but the neuronal system's ability to handle incoming excitatory signals without generating self-sustaining epileptiform discharges undergoes a partial but not complete recovery.

What is the nature of the processes that underlie the apparent recovery to weaker excitation? The early enhancement of the population spike amplitude evoked in the presence of bicuculline recovered to control levels by 1 month (see Fig 1B), indicating that the excitatory network undergoes some form of recovery and is at least partially responsible for the recovery. On the other hand, the early decrease in the efficiency of inhibition also recovered by 1 month (see Fig 1D), suggesting that the recovery process may also involve the inhibitory system. The other side of the same issue concerns the mechanism underlying the incompleteness of the recovery and the processes that contribute the latent period of epileptogenesis found in human head injuries. Our data revealed a progressive increase in the density of mossy fiber sprouting, which is often associated with enhanced recurrent excitation and epileptiform discharges. The increase in the density of mossy fiber sprouting with time could be one candidate underlying the late appearance of hyperexcitability in human head injuries, and it may contribute to the incompleteness of the recovery of the system's stability in response to repetitive stimuli. Interestingly, supragranular mossy fiber sprouting is present in tissue from temporal lobe epilepsy patients with a history of head injury, ${ }^{27,28}$ and the sprouting of excitatory axons has also been reported in the cortical undercut model of posttraumatic hyperexcitability. ${ }^{51}$ It is likely that the degree of sprouting in animal models of head injury depends on several factors, including strain differences, injury paradigm, and impact strength. For example, robust mossy fiber sprouting has been reported after weight-drop head injury, ${ }^{52}$ whereas no mossy fiber sprouting ${ }^{29,30}$ was found after FPI that resulted in lower levels of hilar cell loss than what takes place under our conditions following FPI at 2.0 to 2.2atm impact strength. Our data also indicate that mossy fiber sprouting after FPI can be detected within 1 week after injury, similar to the early time course for sprouting reported in models of epilepsy. ${ }^{19,25}$ In light of the early occurrence and progressive nature of the posttraumatic mossy fiber sprouting, it is possible that sprouting plays a role in hippocampal hyperexcitabilty at both 1 week and 3 months after FPI. It is also interesting to note that, although it was not a focus of this study, our data also revealed an age-dependent decrease in the efficiency of inhibition (see Fig 1D) and a decrease in granule cell sIPSC frequency (increase in IEI), both in control and in post-FPI animals. Age-dependent alterations in functional synaptic connections taking place in cortical networks ${ }^{53}$ are likely to contribute to these phenomena.

The recovery of the early posttraumatic decrease in the efficiency of inhibition to age-matched control levels, as tested with low-frequency stimulation, took place without a complete recovery of the ability of the neuronal network to handle high-frequency excitatory inputs. Furthermore, the increased spontaneous IPSC frequency remained significantly elevated even 5 to 6 months following FPI. As discussed elsewhere, in several models of epilepsy an increase in certain parameters of $\mathrm{GABA}_{\mathrm{A}}$ receptor mediated inhibition has been reported, including increases in $\mathrm{GABA}_{\mathrm{A}}$ receptor numbers, ${ }^{44,54,55}$ changes in $\mathrm{GABA}_{\mathrm{A}}$ receptor subunit composition, ${ }^{55,56}$ and presynaptic enhancement of GABA release. ${ }^{57}$ However, the relationship between enhanced inhibition and hyperexcitability is not fully understood. Zinc-dependent collapse of elevated inhibition, ${ }^{44}$ altered ratio of dendritic versus somatic inhibition, ${ }^{58}$ frequencydependent conversion of increased inhibition to hyperexcitability caused by persistently modified h-channels in postsynaptic cells, ${ }^{59}$ and a preferential collapse of $\mathrm{Cl}^{-}$ homeostasis in dendrites of principal cells ${ }^{60}$ may all play complex roles in determining the efficacy of potentiated inhibitory processes in an ultimately hyperexcitable network. Increased sIPSC frequency that is sensitive to blockade of ionotropic glutamate receptors, similar to our data, has also been reported in kindred animals. ${ }^{44}$ Whether the increased excitatory drive to dentate interneurons, suggested by the data from kindred animals and from our study, actually originates from the sprouted mossy fibers is not known. Shortly after FPI (within hours), there is also an elevated sIPSC frequency in granule cells, which is associated with increased inter- 
neuronal spontaneous firing rates caused by a $\mathrm{Na}^{+}$ pump-dependent shift in the interneuronal resting membrane potential. ${ }^{61}$ However, the posttraumatic elevation of the interneuronal resting membrane potential is transient, as it returns to nonsignificant levels by 4 days after FPI. ${ }^{61}$ Therefore, it is likely that the elevated frequency of the sIPSCs in granule cells from head-injured animals has different underlying mechanisms at different time points following impact.

Taken together, the results demonstrate long-term alterations in both the excitatory and inhibitory networks in the hippocampus after traumatic brain injury in experimental animals. The persistent decrease in seizure threshold indicates the possibility that in human head injuries, particularly after severe injury, the neuronal networks are persistently altered in the limbic system, even if spontaneous behavioral or electrical seizures are not present. Future investigations aimed at understanding the activity-dependent epileptogenic processes ${ }^{50}$ in various experimental models of head trauma will be needed to shed light on the interaction, importance, and the pro- versus antiepileptic nature of the cellular and synaptic alterations triggered by a brain injury episode.

I.S. was financially supported by the National Institutes of Health (NS35915).

We thank Dr O. Steward for his support; and R. Zhu for expert technical assistance.

\section{References}

1. Annegers JF, Grabow JD, Groover RV, et al. Seizures after head trauma: a population study. Neurology 1980;30(7 Pt 1): 683-689.

2. Annegers JF, Hauser WA, Coan SP, Rocca WA. A populationbased study of seizures after traumatic brain injuries. N Engl J Med 1998;338:20-24.

3. Caveness WF, Meirowsky AM, Rish BL, et al. The nature of posttraumatic epilepsy. J Neurosurg 1979;50:545-553.

4. Angeleri F, Majkowski J, Cacchiò G, et al. Posttraumatic epilepsy risk factors: one-year prospective study after head injury. Epilepsia 1999;40:1222-1230.

5. Jennet B. Epilepsy after nonmissile head injuries. London: Heinemann, 1975.

6. Salazar AM, Jabbari B, Vance SC, et al. Epilepsy after penetrating head injury. I. Clinical correlates: a report of the Vietnam Head Injury Study. Neurology 1985;35:1406-1414.

7. Willmore JL. Posttraumatic epilepsy: cellular mechanisms and implications for treatment. Epilepsia 1990;31:S67-S73.

8. McIntosh TK, Vink R, Noble L, et al. Traumatic brain injury in the rat: characterization of a lateral fluid-percussion model. Neuroscience 1989;28:233-244.

9. Lowenstein DH, Thomas MJ, Smith DH, McIntosh TK. Selective vulnerability of dentate hilar neurons following traumatic brain injury: a potential mechanistic link between head trauma and disorders of the hippocampus. J Neurosci 1992;12: $4846-4853$.

10. Toth Z, Hollrigel GS, Gorcs T, Soltesz I. Instantaneous perturbation of dentate interneuronal networks by a pressure wavetransient delivered to the neocortex. J Neurosci 1997;17: $8106-8117$.
11. Margerison JH, Corsellis JA. Epilepsy and the temporal lobes. A clinical, electroencephalographic and neuropathological study of the brain in epilepsy, with particular reference to the temporal lobes. Brain 1966;89:499-530.

12. Bruton C. The neuropathology of temporal lobe epilepsy. New York: Oxford University Press, 1988.

13. Santhakumar V, Bender R, Frotscher M, et al. Granule cell hyperexcitability in the early posttraumatic rat dentate gyrus: the 'irritable mossy cell' hypothesis. J Physiol 2000;524(Pt 1): 117-134.

14. Coulter DA, Rafiq A, Shumate M, et al. Brain injury-induced enhanced limbic epileptogenesis: anatomical and physiological parallels to an animal model of temporal lobe epilepsy. Epilepsy Res 1996;26:81-91.

15. Pierce JE, Smith DH, Trojanowski JQ, McIntosh TK. Enduring cognitive, neurobehavioral and histopathological changes persist for up to one year following severe experimental brain injury in rats. Neuroscience 1998;87:359-369.

16. Bramlett HM, Dietrich WD, Green EJ, Busto R. Chronic histopathological consequences of fluid-percussion brain injury in rats: effects of posttraumatic hypothermia. Acta Neuropathol 1997;93:190-199.

17. Smith DH, Chen XH, Pierce JE, et al. Progressive atrophy and neuron death for one year following brain trauma in the rat. J Neurotrauma 1997;14:715-727.

18. Sanders MJ, Sick TJ, Perez-Pinzon MA, et al. Chronic failure in the maintenance of long-term potentiation following fluid percussion injury in the rat. Brain Res 2000;861:69-76.

19. Sutula T, Cascino G, Cavazos J, et al. Mossy fiber synaptic reorganization in the epileptic human temporal lobe. Ann Neurol 1989;26:321-330.

20. Houser CR, Miyashiro JE, Swartz BE, et al. Altered patterns of dynorphin immunoreactivity suggest mossy fiber reorganization in human hippocampal epilepsy. J Neurosci 1990;10:267-282.

21. Babb TL, Kupfer WR, Pretorius JK, et al. Synaptic reorganization by mossy fibers in human epileptic fascia dentata. Neuroscience 1991;42:351-363.

22. Zhang N, Houser CR. Ultrastructural localization of dynorphin in the dentate gyrus in human temporal lobe epilepsy: a study of reorganized mossy fiber synapses. J Comp Neurol 1999;405: 472-490.

23. Tauck DL, Nadler JV. Evidence of functional mossy fiber sprouting in hippocampal formation of kainic acid-treated rats. J Neurosci 1985;5:1016-1022.

24. Sutula T, He XX, Cavazos J, Scott, G. Synaptic reorganization in the hippocampus induced by abnormal functional activity. Science 1988;239:1147-1150.

25. Cavazos JE, Golarai G, Sutula TP. Mossy fiber synaptic reorganization induced by kindling: time course of development, progression, and permanence. J Neurosci 1991;11:2795-2803.

26. Okazaki MM, Evenson DA, Nadler JV. Hippocampal mossy fiber sprouting and synapse formation after status epilepticus in rats: visualization after retrograde transport of biocytin. J Comp Neurol 1995;352:515-534.

27. Mathern GW, Pretorius JK, Babb TL. Influence of the type of initial precipitating injury and at what age it occurs on course and outcome in patients with temporal lobe seizures. J Neurosurg 1995;82:220-227.

28. Jeub M, Lie A, Blümcke I, et al. Loss of dynorphin-mediated inhibition of voltage-dependent $\mathrm{Ca}^{2+}$ currents in hippocampal granule cells isolated from epilepsy patients is associated with mossy fiber sprouting. Neuroscience 1999;94:465-471.

29. Hill SJ, Barberese E, Gennarelli TA, McIntosh TK. The potential role for reactive astrocytes in CNS reinnervation following experimental brain injury in rat. Soc Neurosci Abstr 1994;20: 424. 
30. Shumate M, Rafiq A, Lyeth B, et al. Traumatic brain injury produces loss of neurons in hilus and CA3 but no significant mossy fiber sprouting in the hippocampus. Epilepsia 1995; 36(S4): 118 .

31. Soltesz I, Mody I. Patch-clamp recordings reveal powerful GABAergic inhibition in dentate hilar neurons. J Neurosci 1994;14:2365-2376.

32. Rafiq A, DeLorenzo RJ, Coulter DA. Generation and propagation of epileptiform discharges in a combined entorhinal cortex/ hippocampal slice. J Neurophysiol 1993;70:1962-1974.

33. Rafiq A, Zhang YF, DeLorenzo RJ, Coulter DA. Long-duration self-sustained epileptiform activity in the hippocampalparahippocampal slice: a model of status epilepticus. J Neurophysiol 1995;74:2028-2042.

34. Dube C, Chen K, Eghbal-Ahmadi M, et al. Prolonged febrile seizures in the immature rat model enhance hippocampal excitability long term. Ann Neurol 2000;47:336-344.

35. Soltesz I, Smetters DK, Mody I. Tonic inhibition originates from synapses close to the soma. Neuron 1995;14:1273-1283.

36. Hollrigel GS, Toth K, Soltesz I. Neuroprotection by propofol in acute mechanical injury: role of GABAergic inhibition. J Neurophysiol 1996;76:2412-2422.

37. Danscher G. Histochemical demonstration of heavy metals. A revised version of the sulphide silver method suitable for both light and electronmicroscopy. Histochemistry 1981;71:1-16.

38. Halasy K, Somogyi P. Distribution of GABAergic synapses and their targets in the dentate gyrus of rat: a quantitative immunoelectron microscopic analysis. J Hirnforsch 1993;34: 299-308.

39. Freund TF, Buzsáki G. Interneurons of the hippocampus. Hippocampus 1996;6:347-470.

40. Dreier JP, Heinemann U. Regional and time dependent variations of low $\mathrm{Mg} 2+$ induced epileptiform activity in rat temporal cortex slices. Exp Brain Res 1991;87:581-596.

41. Davies CH, Davies SN, Collingridge GL. Paired-pulse depression of monosynaptic GABA-mediated inhibitory postsynaptic responses in rat hippocampus. J Physiol 1990;424:513-531.

42. Otis TS, Mody I. Modulation of decay kinetics and frequency of $\mathrm{GABA}_{\mathrm{A}}$ receptor-mediated spontaneous inhibitory postsynaptic currents in hippocampal neurons. Neuroscience 1992;49: 13-32.

43. Buhl EH, Halasy K, Somogyi P. Diverse sources of hippocampal unitary inhibitory postsynaptic potentials and the number of synaptic release sites. Nature 1994;368:823-828.

44. Buhl EH, Otis TS, Mody I. Zinc-induced collapse of augmented inhibition by GABA in a temporal lobe epilepsy model. Science 1996;271:369-373.

45. Prince DA, Jacobs K. Inhibitory function in two models of chronic epileptogenesis. Epilepsy Res 1998;32:83-92.

46. Goldstein M. Traumatic brain injury: a silent epidemic. Ann Neurol 1990;27:327.
47. Max W, MacKenize EJ, Rice DP. Head injuries: costs and consequences. J Head Trauma Rehabil 1991;6:76-91.

48. Temkin NR, Dikmen SS, Anderson GD, et al. Valproate therapy for prevention of posttraumatic seizures: a randomized trial. J Neurosurg 1999;91:593-600.

49. Temkin NR, Dikmen SS, Winn HR. Clinical trials for seizure prevention. Adv Neurol 1998;76:179-188.

50. Graber KD, Prince DA. Tetrodotoxin prevents posttraumatic epileptogenesis in rats. Ann Neurol 1999;46:234-242.

51. Salin P, Tseng GF, Hoffman S, et al. Axonal sprouting in layer $\mathrm{V}$ pyramidal neurons of chronically injured cerebral cortex. J Neurosci 1995;15:8234-8245.

52. Golari G, Greenwood AC, Feeney DM, Connor JA. Traumatic brain injury (TBI) induces sprouting and mossy fiber reorganization of the mossy fiber pathway in the dentate gyrus of the hippocampus. Soc Neurosci Abstr 1998;24:1728.

53. Wong TP, Marchese G, Casu MA, et al. Loss of presynaptic and postsynaptic structures is accompanied by compensatory increase in action potential-dependent synaptic input to layer $\mathrm{V}$ neocortical pyramidal neurons in aged rats. J Neurosci 2000; 20:8596-8606.

54. Otis TS, De Koninck Y, Mody I. Lasting potentiation of inhibition is associated with an increased number of gammaaminobutyric acid type A receptors activated during miniature inhibitory postsynaptic currents. Proc Natl Acad Sci U S A 1994;91:7698-7702.

55. Nusser Z, Hájos N, Somogyi P, Mody I. Increased number of synaptic $\mathrm{GABA}_{\mathrm{A}}$ receptors underlies potentiation at hippocampal inhibitory synapses. Nature 1998;395:172-177.

56. Brooks-Kayal AR, Shumate MD, Jin $H$, et al. Selective changes in single cell $\mathrm{GABA}_{\mathrm{A}}$ receptor subunit expression and function in temporal lobe epilepsy. Nat Med 1998;4: $1166-1172$.

57. Chen K, Baram TZ, Soltesz I. Febrile seizures in the developing brain result in persistent modification of neuronal excitability in limbic circuits. Nat Med 1999;5:888-894.

58. Cossart R, Dinocourt C, Hirsch JC, et al. Dendritic but not somatic GABAergic inhibition is decreased in experimental epilepsy. Nat Neurosci 2001;4:52-62.

59. Chen K, Aradi I, Thon N, et al. Persistently modified $\mathrm{H}$-channels after complex febrile seizures convert the seizureinduced enhancement of inhibition to hyperexcitability. Nat Med 2001;7:331-337.

60. Staley KJ, Soldo BL, Proctor WR. Ionic mechanisms of neuronal excitation by inhibitory $\mathrm{GABA}_{\mathrm{A}}$ receptors. Science 1995;269: 977-981.

61. Ross ST, Soltesz I. Selective depolarization of interneurons in the early posttraumatic dentate gyrus: involvement of the $\mathrm{Na}(+) / \mathrm{K}(+)$-ATPase. J Neurophysiol 2000;83:2916-2930. 